\title{
Facile high-throughput forward chemical genetic screening by in situ monitoring of glucuronidase-based reporter gene expression in Arabidopsis thaliana
}

\section{Vivek Halder and Erich Kombrink*}

Chemical Biology Laboratory, Max Planck Institute for Plant Breeding Research, Cologne, Germany

Edited by:

Markus Kaiser, University of

Duisburg-Essen, Germany

\section{Reviewed by:}

Paul Overvoorde, Macalester

College, USA

Yoshiteru Noutoshi, Okayama

University, Japan

*Correspondence:

Erich Kombrink, Chemical Biology Laboratory, Max Planck Institute for

Plant Breeding Research,

Carl-von-Linné-Weg 10, 50829

Cologne, Germany

e-mail: kombrink@mpipz.mpg.de
The use of biologically active small molecules to perturb biological functions holds enormous potential for investigating complex signaling networks. However, in contrast to animal systems, the search for and application of chemical tools for basic discovery in the plant sciences, generally referred to as "chemical genetics," has only recently gained momentum. In addition to cultured cells, the well-characterized, small-sized model plant Arabidopsis thaliana is suitable for cultivation in microplates, which allows employing diverse cell- or phenotype-based chemical screens. In such screens, a chemical's bioactivity is typically assessed either through scoring its impact on morphological traits or quantifying molecular attributes such as enzyme or reporter activities. Here, we describe a facile forward chemical screening methodology for intact Arabidopsis seedlings harboring the $\beta$-glucuronidase (GUS) reporter by directly quantifying GUS activity in situ with 4-methylumbelliferyl- $\beta$-D-glucuronide (4-MUG) as substrate. The quantitative nature of this screening assay has an obvious advantage over the also convenient histochemical GUS staining method, as it allows application of statistical procedures and unbiased hit selection based on threshold values as well as distinction between compounds with strong or weak bioactivity. At the same time, the in situ bioassay is very convenient requiring less effort and time for sample handling in comparison to the conventional quantitative in vitro GUS assay using 4-MUG, as validated with several Arabidopsis lines harboring different GUS reporter constructs. To demonstrate that the developed assays is particularly suitable for large-scale screening projects, we performed a pilot screen for chemical activators or inhibitors of salicylic acid-mediated defense signaling using the Arabidopsis PR1p::GUS line. Importantly, the screening methodology provided here can be adopted for any inducible GUS reporter line.

Keywords: chemical screening, chemical genetics, high-throughput screening, bioactive small molecules, $\beta$-glucuronidase activity, reporter gene expression, salicylic acid

\section{INTRODUCTION}

In search for new tools that aid the dissection of complex biological processes, chemical genetics has been recognized as alternative experimental strategy to classical genetics approaches. Its strength lies in the potential to circumvent problems that are commonly encountered in classical genetics, such as redundancy, lethality, or pleiotropy of gene functions (Blackwell and Zhao, 2003; Stockwell, 2004; Hicks and Raikhel, 2012). For example, small molecules can in principle target multiple members of a protein family or, alternatively, the effects they exert can be temporally controlled and possibly reversed by withdrawing the chemical from the system. However, in contrast to animal systems, which are nurtured from drug discovery programs and cancer research, the application of chemical genetics in basic plant research stands quite in contrast to industrial applications such as pesticide (herbicide and fungicide) discovery and has only recently found broader application as documented in a number of reviews (Blackwell and Zhao, 2003; Raikhel and Pirrung, 2005;
Kaschani and van der Hoorn, 2007; Hicks and Raikhel, 2009, 2012, 2014; Tóth and van der Hoorn, 2010).

Fundamentally, the key similar feature between chemical genetics and classical genetics is the generation of recognizable phenotypes at the whole plant, organ, cell, or subcellular level. While in genetic approaches phenotypes are created by mutations that result in altered protein expression or function, chemicals mostly interfere with protein functions directly, but when this alteration affects transcription factors or upstream components it may also result in modified gene expression. Correspondingly, numerous screenable phenotypes can be used for chemical interference and the model plant Arabidopsis thaliana is particularly suitable for such approaches. This is not only because of its small size, permitting easy cultivation in 96-well microplate format either on agar or in liquid medium, but also because large collections of mutants and transgenic lines are available, allowing to perform a diversity of phenotypic and reporter-based chemical screening strategies. Likewise, cultured cells are a prime 
choice for chemical screens. However, screening at the whole plant level offers its own advantages to monitor morphological responses that are dependent on multicellular structures such as root growth, cell-wall formation, seed germination, hypocotyl elongation and other developmental processes, as well as organand cell-type-specific gene expression via selective reporter readouts. In recent years, numerous chemical screens covering many areas of plant biology have demonstrated the increasing impact of chemical genetics on basic plant research, including some impressive success stories in which for selected small molecules the cognate targets have been identified (Hicks and Raikhel, 2014). There are multiple examples addressing questions related to plant hormone signaling, i.e., responses to auxin, abscisic acid (ABA), jasmonic acid (JA), or brassinosteroids (Hayashi et al., 2003, 2008; Zhao et al., 2003; Armstrong et al., 2004; Walsh et al., 2006; Gendron et al., 2008; De Rybel et al., 2009; Park et al., 2009; Meesters et al., 2014), endomembrane trafficking (Zouhar et al., 2004; Surpin et al., 2005; DeBolt et al., 2007; Rojas-Pierce et al., 2007; Kim et al., 2010), plant pathogen interactions and plant immune responses (Serrano et al., 2007, 2010; Schreiber et al., 2008; Knoth et al., 2009; Noutoshi et al., 2012), and cellulose biosynthesis resp. cell wall formation (Desprez et al., 2002; Yoneda et al., 2007; Park et al., 2014). However, the most impressive example of groundbreaking work with small molecules was the identification and use of a novel ABA agonist, pyrabactin, that led to the identification of the long-searched-for ABA receptor (Melcher et al., 2009; Park et al., 2009; Santiago et al., 2009; Cutler et al., 2010).

In plant chemical genetic screens, the GUS reporter system has frequently been used. The simplicity and easiness of the histochemical GUS staining method, which relies on cleavage of 5-bromo-4-chloro-3-indolyl- $\beta$-D-glucuronide (X-Gluc) and formation of a blue-colored precipitate, made this approach a suitable and preferred choice for monitoring activity (phenotypic evaluation) in large-scale chemical screening approaches (Hayashi et al., 2003; Armstrong et al., 2004; Serrano et al., 2007; Gendron et al., 2008; Knoth et al., 2009). However, on the down side, this method provides only qualitative data, which are prone to subjective decisions and biased hit selection. Alternatively, GUS activity can be quantitatively determined by spectrophotometrical or fluorimetrical assays monitoring the cleavage of p-nitrophenyl- $\beta$-D-glucuronide or 4-methylumbelliferyl- $\beta$ D-glucuronide (4-MUG), respectively (Jefferson et al., 1987). Although reliable and robust, the shortcomings of these assays are that they are labor-intensive and time-consuming, as they require tissue homogenization and protein extraction, which renders these assays unsuitable for screening of large libraries. Alternatively, luciferase- or GFP-based reporter systems, allowing monitoring of true in vivo activities, are also suitable for chemical screening, but as these systems are less abundant than GUS-based reporters, there are only few documented applications (Yoneda et al., 2007; Tóth et al., 2012; Forde et al., 2013; Motte et al., 2013; Meesters et al., 2014).

Since GUS is the prevailing reporter system in plants, we wanted to combine the best out of both outlined approaches of GUS activity determination for a screening platform, and thus we explored whether the ease of the histochemical GUS staining method could be merged with the advantages of quantitative enzyme assays. To this end, we have established a simple chemical screening methodology, which is based on detergent-facilitated infusion of 4-MUG substrate through any GUS expressing plant tissue and direct quantification of fluorescence emitted by the released 4-methylumbelliferone (4-MU) in the same solution (Blázquez, 2007). Importantly, this assay is not only fast, robust and reliable, but also provides quantitative (or semi-quantitative) data directly in situ, thereby minimizing sample handling and allowing unbiased identification of hits via numeric threshold values derived from statistical procedures (Malo et al., 2006; Birmingham et al., 2009). To demonstrate the potential and superiority of our screening methodology, we used the transgenic $A$. thaliana line harboring the salicylic acid (SA)-responsive $P R 1 p:: G U S$ reporter to screen separately for both activators and inhibitors of SA signaling. PATHOGENESIS-RELATED 1 (PR1) is as a canonical SA marker gene, regulated by multiple transcription factors, such as TGAs and WRKYs, and it is robustly up-regulated upon plant infection with biotrophic pathogens and during the systemic immune response (Vlot et al., 2009; Tsuda et al., 2013). In this small pilot experiment, we faithfully identified the known strong activator acetylsalicylic acid (ASA) and the translation inhibitor cycloheximide (CHX), but additional modulators of $P R 1$ gene expression that exert only weak effects were also captured. Thus, as expected from a quantitative assay, our method enables facile, automatic data acquisition and can also reliably distinguish between compounds with high and low potency. With this facile method at hand, largescale screening campaigns using any GUS-expressing Arabidopsis line can be carried out in a time-, labor-, and cost-effective manner.

\section{MATERIALS AND METHODS PLANT MATERIAL AND GROWTH CONDITIONS}

In this study we used $A$. thaliana Columbia-0 (Col-0) transgenic lines carrying the following reporter genes in the Col-0 (or Col5) genomic background: PR1p::GUS (Shapiro and Zhang, 2001), DR5::GUS (Ulmasov et al., 1997), WRKY29p::GUS (Serrano et al., 2007), and DC3::GUS (Chak et al., 2000). Arabidopsis seeds were surface-sterilized and seedlings grown hydroponically in 96well microplates (PerkinElmer Inc., Germany) containing $0.2 \mathrm{ml}$ of half-strength MS basal salt medium (Murashige and Skoog, 1962) supplemented with $0.5 \%$ sucrose. After stratification for 2 days at $4^{\circ} \mathrm{C}$ in the dark, plates were placed for 12 days in a growth chamber at a day/night cycle of $16 / 8 \mathrm{~h}$ at $21 / 19^{\circ} \mathrm{C}$, respectively.

\section{ANALYSIS OF GENE EXPRESSION IN GUS REPORTER LINES}

Gene expression of $\beta$-glucuronidase (GUS) reporter lines was induced by treatment with the appropriate phytohormones as previously reported to yield maximum activity, i.e., PR1p::GUS was treated with $200 \mu \mathrm{M}$ SA for $24 \mathrm{~h}, D R 5 p:: G U S$ with $5 \mu \mathrm{M}$ indole 3-acetic acid (IAA) for $4 \mathrm{~h}, D C 3 p:: G U S$ with $100 \mu \mathrm{M}$ ABA for $24 \mathrm{~h}$, and WRKY29p::GUS with $1 \mu \mathrm{M}$ peptide epitope of bacterial flagellin (flg22) for $4 \mathrm{~h}$. Following this treatment, the medium was removed by aspiration and seedlings were used immediately (or stored at $-80^{\circ} \mathrm{C}$ ) for quantification of 
GUS activity by in situ or in vitro assays. To reveal the organand cell-type-specific expression patterns of reporter genes, histochemical GUS staining was performed with the chromogenic substrate 5-bromo-4-chloro-3-indolyl- $\beta$-D-glucuronide (X-gluc) as previously described (Ancillo et al., 2003) using 12-day-old seedlings after treatment as specified above.

\section{Quantification of GUS activity in vitro}

The quantitative GUS assay was carried out as previously described (Sprenger-Haussels and Weisshaar, 2000). In brief, tissue samples (1-4 seedlings corresponding to $20-100 \mathrm{mg}$ ) were transferred to microtubes, homogenized in extraction buffer ( $100 \mathrm{mM}$ potassium phosphate, $1 \mathrm{mM} \mathrm{DTT}, \mathrm{pH} 7.5)$ and debris removed by centrifugation $\left(30 \mathrm{~min}, 13,000 \mathrm{~g}, 4^{\circ} \mathrm{C}\right)$. The clear supernatant $(50 \mu \mathrm{L})$ was mixed with GUS assay buffer $(50 \mu \mathrm{L})$ containing $2 \mathrm{mM} 4$-methylumbelliferyl- $\beta$-D-glucuronide (4-MUG), $50 \mathrm{mM}$ Na-phosphate $\mathrm{pH}$ 7.0, $1 \mathrm{mM}$ EDTA, 0.1\% Triton X-100, $10 \mathrm{mM} \beta$-mercaptoethanol. Aliquots $(20 \mu \mathrm{L})$ were sampled after 0,30 , and $60 \mathrm{~min}$ incubation at $37^{\circ} \mathrm{C}$ (unless otherwise stated), mixed with $0.2 \mathrm{~mL} 0.2 \mathrm{M} \mathrm{Na}_{2} \mathrm{CO}_{3}$ and 4-MU fluorescence was determined in a microplate reader (FluoroCount, Packard Bioscience, Meriden, Connecticut) using an excitation/emission wavelength of 365/455 nm. GUS activity was calculated using the $\Delta \mathrm{E}_{455}$ increments (0-30 and 30-60 min) and appropriate $4-\mathrm{MU}$ standards $(50-5000 \mathrm{pmol})$. Specific activities were related to the protein concentration determined according to Bradford (Bradford, 1976) with bovine serum albumin as standard. All reported values are the mean $( \pm S D)$ of at least four biological replicates.

\section{Quantification of GUS activity in intact seedlings (in situ)}

To adjust the quantitative GUS assay for large-scale screening applications, we optimized a previously reported method (Blázquez, 2007) by minimizing handling time and effort. In brief, single 12-day-old seedlings grown in 96-well microplates were incubated with $150 \mu \mathrm{L}$ lysis buffer $(50 \mathrm{mM}$ sodium phosphate, $\mathrm{pH} 7.0,10 \mathrm{mM}$ EDTA, $0.1 \%$ Triton X-100) containing $1 \mathrm{mM} 4$-MUG at $37^{\circ} \mathrm{C}$ for $90 \mathrm{~min}$, unless otherwise stated. Of note, seedlings should be completely submerged in lysis buffer to allow ubiquitous substrate supply. At the end of the incubation period, $50 \mu \mathrm{L} 1 \mathrm{M} \mathrm{Na}_{2} \mathrm{CO}_{3}$ (stop solution) was added to each well and 4-MU fluorescence directly determined in a microplate reader as before (excitation/emission wavelength of 365/455 nm). Activity is either directly expressed as relative light units (RLU per assay or seedling) or was converted to molar units using a standard curve (150 $\mu \mathrm{L} 50-1000 \mu \mathrm{M} 4$-MU in lysis buffer, plus $50 \mu \mathrm{L}$ stop solution). All results are typically the mean $( \pm \mathrm{SD})$ of at least four biological replicates.

\section{CHEMICAL LIBRARY SCREENING}

A small compound library, comprising 40 hand-picked chemicals (1 mM dissolved in DMSO), was used for screening. Arabidopsis seedlings harboring the PR1p::GUS reporter were grown in 96well microplates for 12 days and before chemical treatment, growth medium was removed and replaced by fresh half-strength MS medium. To conditionally modulate SA signaling, seedlings were pretreated with chemicals (dissolved in DMSO) at a final concentration of $20 \mu \mathrm{M}$ for $1 \mathrm{~h}$ before addition of $200 \mu \mathrm{M}$ SA (dissolved in DMSO) to induce PR1p::GUS expression and subsequent incubation for $24 \mathrm{~h}$ unless otherwise stated (screening for inhibitors). Alternatively, omission of SA allowed screening for activators of PR1p::GUS expression. All chemicals were analyzed in two replicates and their activity normalized to control samples (without added chemical) that were contained on the same microplate (first and last column). The organization of samples in 96-well microplates is shown in Figure 1.

\section{STATISTICAL ANALYSIS}

The quantitative data analysis was performed in Excel spreadsheets with the embedded basic statistical functions (mean, standard deviation, Student's $t$-test, r.m.s. linear regression).

A common quality metric for evaluation and validation of high-throughput screening assays are the $Z$ and $Z^{\prime}$ factors (Zhang et al., 1999; Birmingham et al., 2009). The $Z$ ' factor, often used during assay optimization, relies on high-value (positive) and low-value (negative) controls and is calculated by Equation (1), with $\mu$ representing the mean and $\sigma$ the standard deviation of the high-value (subscript "hc") and low-value (subscript "lc") controls, respectively.

$$
Z^{\prime} \text { factor }=1-\frac{\left(3 \sigma_{h c}+3 \sigma_{l c}\right)}{\left|\mu_{h c}-\mu_{l c}\right|}
$$

The $Z$ ' factor ranges from negative infinity to 1 , with values $>0.5$ indicating an excellent assay, $>0$ an acceptable assays and $<0$ an unacceptable assay. Correspondingly, the $Z$ factor may be calculated using actual screening data (high values) instead of separate positive control values and thus serves to directly assess performance of the screen (Zhang et al., 1999; Birmingham et al., 2009).

The $Z$ score, not to be confused with the $Z$ and $Z$ ' factors, representing the number of standard deviations from the mean, is frequently used to normalize screening data such that individual

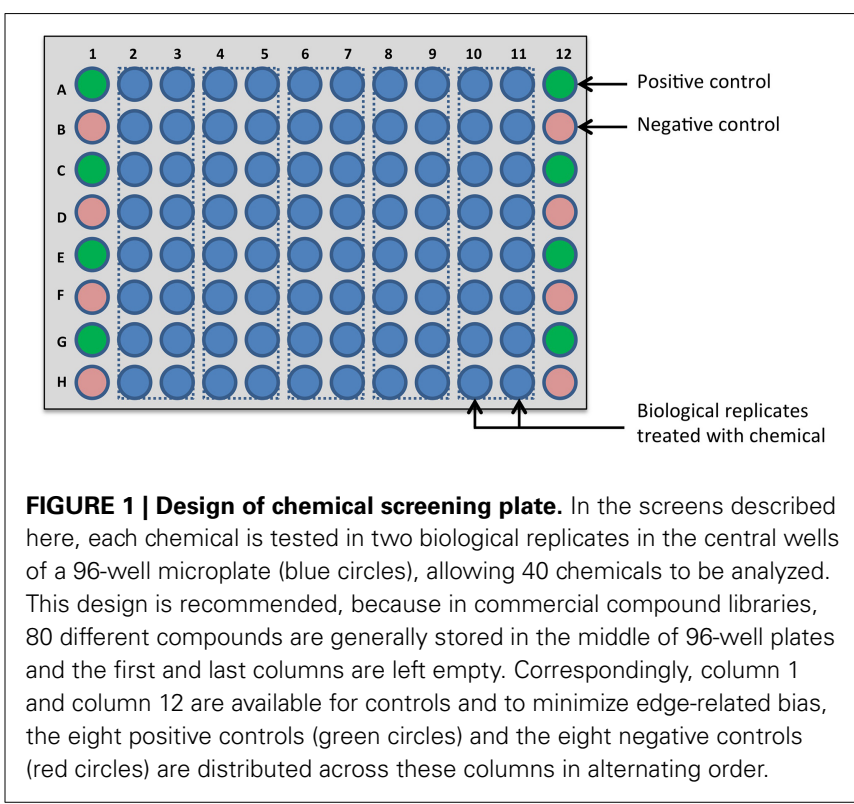



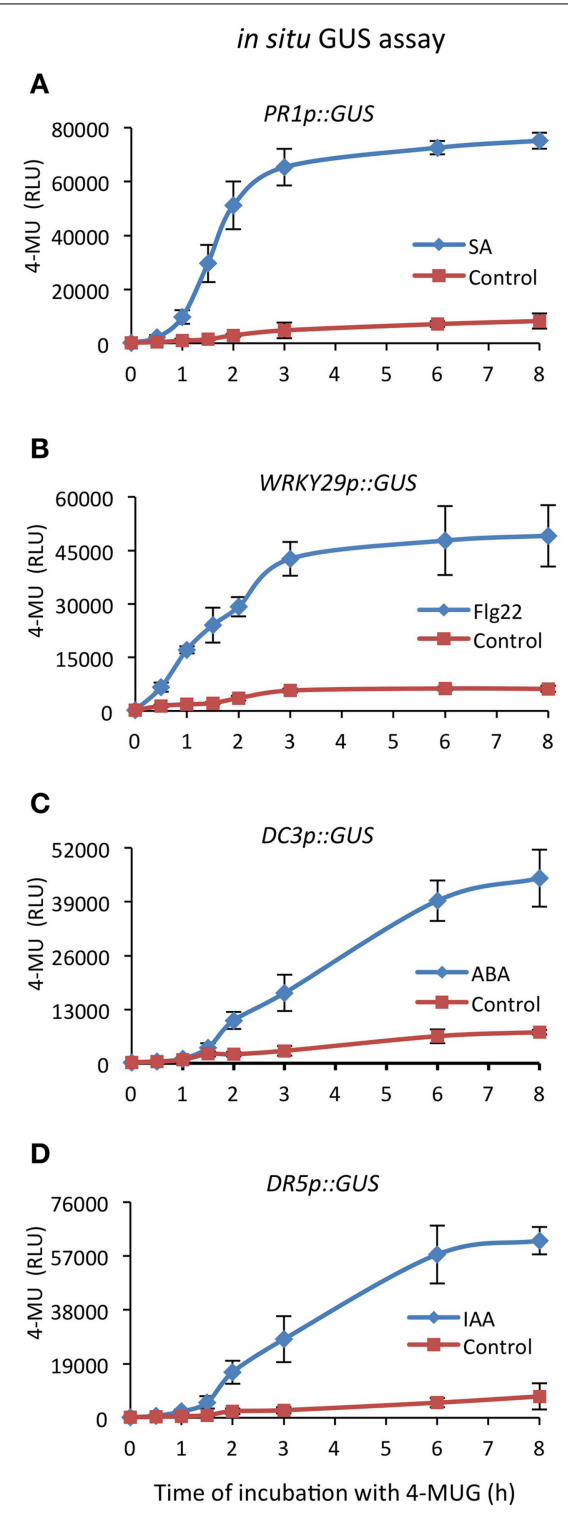

FIGURE 2 | Comparison of GUS activity determined in whole seedlings (in situ) and in protein extracts (in vitro). Seedlings of transgenic Arabidopsis thaliana lines harboring different inducible promoter-GUS fusions were grown for 12 days hydroponically in microplates and then treated with the respective inducer (or solvent as control) for an appropriate time period to obtain high expression levels of the reporters. (A,E) PR1p::GUS seedlings received $200 \mu \mathrm{M}$ SA for $24 \mathrm{~h},(\mathbf{B}, \mathbf{F})$ WRKY29p::GUS received $1 \mu \mathrm{M}$ flg22 for $4 \mathrm{~h},(\mathbf{C}, \mathbf{G})$ DC3p::GUS received $100 \mu \mathrm{M}$ ABA for $24 \mathrm{~h}$ and $\mathbf{( D , H )} D R 5 p:: G U S$ received $5 \mu \mathrm{M} I A A$ for $4 \mathrm{~h}$. Following this treatment, the medium was removed and for monitoring GUS activity in situ (A-D), seedlings were
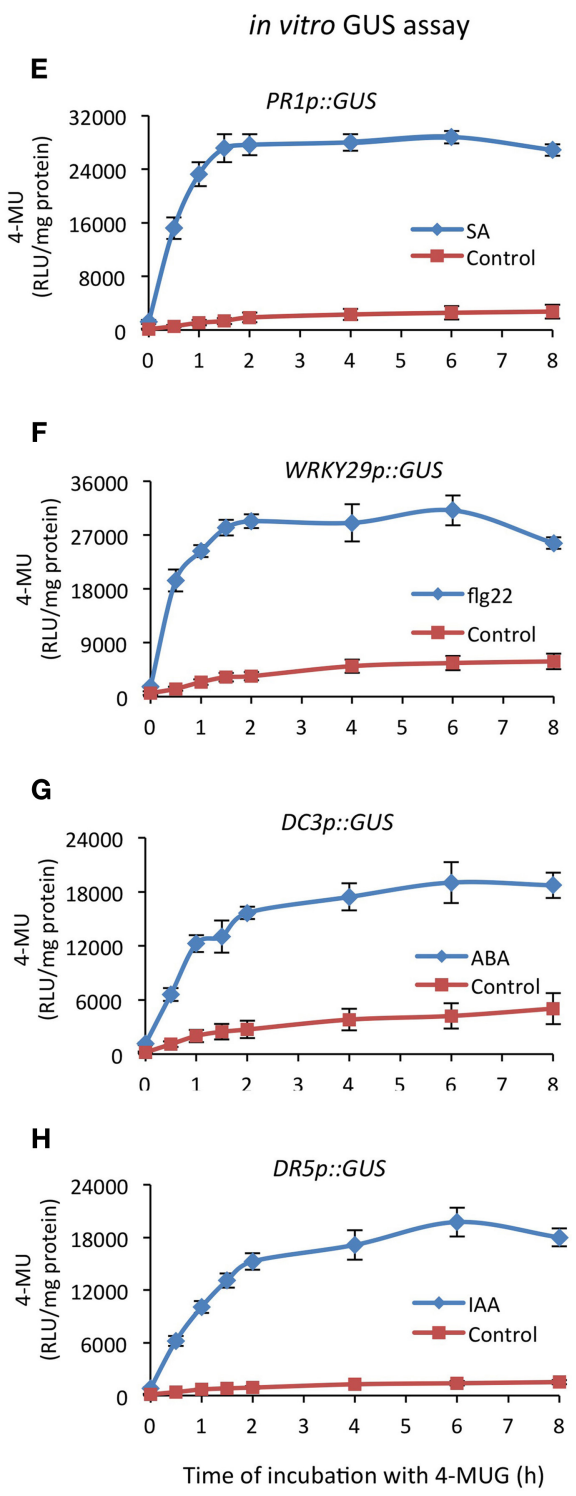

incubated with the substrate 4-MUG $(1 \mathrm{mM})$ for the indicated time periods before the reaction was terminated by addition of stop solution $\left(\mathrm{Na}_{2} \mathrm{CO}_{3}\right)$. The released reaction product, 4-MU, was directly quantified by its fluorescence in a microplate reader. For quantifying GUS activity in vitro (E-H), seedlings were homogenized and conversion of the substrate 4-MUG $(2 \mathrm{mM})$ in clarified protein extracts was determined as described in the Materials and Methods Section. 4-MU release is given in relative light units (RLU) emitted from the whole in situ assay (A-D) or normalized to the protein concentration for the in vitro assay $(\mathbf{E}-\mathbf{H})$. All values represent the mean $( \pm S D)$ of four biological replicates. measurements are rescaled relative to the whole-plate variation (Malo et al., 2006; Birmingham et al., 2009). The $Z$ score was calculated by Equation (2), with $x_{i}$ representing the raw value of the individual compound $i, \mu$ and $\sigma$ are the mean and standard deviation, respectively, of all values within a plate.

$$
Z \text { score }=\frac{x_{i}-\mu}{\sigma}
$$

\section{RESULTS}

\section{DIRECT QUANTIFICATION OF GUS ACTIVITY IN INTACT ARABIDOPSIS} SEEDLINGS

We wanted to establish a facile GUS assay that does not require tissue homogenization and yet provides a reliable, quantitative output that is suitable for large-scale chemical library screening. Therefore, we used Arabidopsis seedlings harboring different inducible GUS reporter constructs, which were grown 
hydroponically in 96-well microplates and treated accordingly to provide high GUS activity. Such seedlings were then directly incubated with GUS assay buffer, which was supplemented with Triton X-100 to enhance the permeability of both the substrate 4-MUG and the product 4-MU throughout the tissue. The release of the product (4-MU, monitored by its fluorescence) occurred with a delay of 20-60 min, followed by a linear increase for about $2 \mathrm{~h}$ until the substrate was depleted (Figure 2). Apparently, the delay of product release is inversely correlated with total GUS activity; strong promoters, such as PR1 or WRKY29 (Figures 2A,B), providing high levels of expression (and enzyme activity) showed shorter delays of substrate release in comparison to DC3 or DR5 (Figures 2C,D), which yield lower expression levels and extended delays.

To confirm that the in situ GUS assay faithfully records activity, we also determined rates of substrate conversion in vitro by a conventional GUS activity assay (Sprenger-Haussels and Weisshaar, 2000), using seedlings that were subjected to the same treatments. As expected, in protein extracts the release of the product (4-MU) occurred instantaneously but otherwise followed a similar time course, as in intact seedlings (Figures 2E-H). Next, we directly compared the specific GUS activity profiles in biological samples, i.e., transgenic Arabidopsis lines harboring different reporter constructs, that were treated accordingly to provide high expression levels of the respective reporter gene. As apparent from Figure 3, our in situ method and the established in vitro GUS assay generally recorded nearly identical induction of activity in response to specific treatments in all tested reporter lines, ranging between 15-fold for PR1p::GUS (SA responsive) and 5-fold for DC3p::GUS (ABA responsive) when comparing positive and negative controls. Of note, the in situ GUS activity in this experiment was determined from a fixed incubation period of $2 \mathrm{~h}$ for all samples, whereas the in vitro activity assay recorded initial rates over maximally $1 \mathrm{~h}$ (cf Figure 2). Therefore, as result of delayed substrate release, the in situ method had a tendency to provide lower values, ranging from a maximum deviation of $-30 \%$ (DR5p::GUS, Figure 3D) to virtually identical values ( $P R 1 p:: G U S$, Figure 3A). From this we conclude that GUS activity can be directly and reliably estimated in intact seedlings, but the conditions need to be adjusted to each particular reporter lines such that product release remains in the linear range (or near linear range) and not all 4-MUG has been consumed. For the PR1p::GUS line, we selected an incubation time of $90 \mathrm{~min}$ for all subsequent experiments (cf Figure 2A).

\section{ROBUST AND RELIABLE GUS OUANTIFICATION IN FRESH AND FROZEN ARABIDOPSIS SEEDLINGS}

To further validate the reliability and robustness of GUS activity quantification in intact seedlings, we applied the in situ GUS assay to analyze the time course of PR1p::GUS expression upon treatment with SA. Here, a standard curve with known 4-MU concentrations was used to normalize the activity, i.e., the emitted fluorescence, which was again compared to the GUS activity determined in vitro. As shown in Figure 4, both assays provide a similar result (i.e., GUS activity profiles), demonstrating that PR1 gene expression is rapidly up-regulated, reaching a maximum at $12 \mathrm{~h}$ and slowly declining thereafter. In control seedlings,
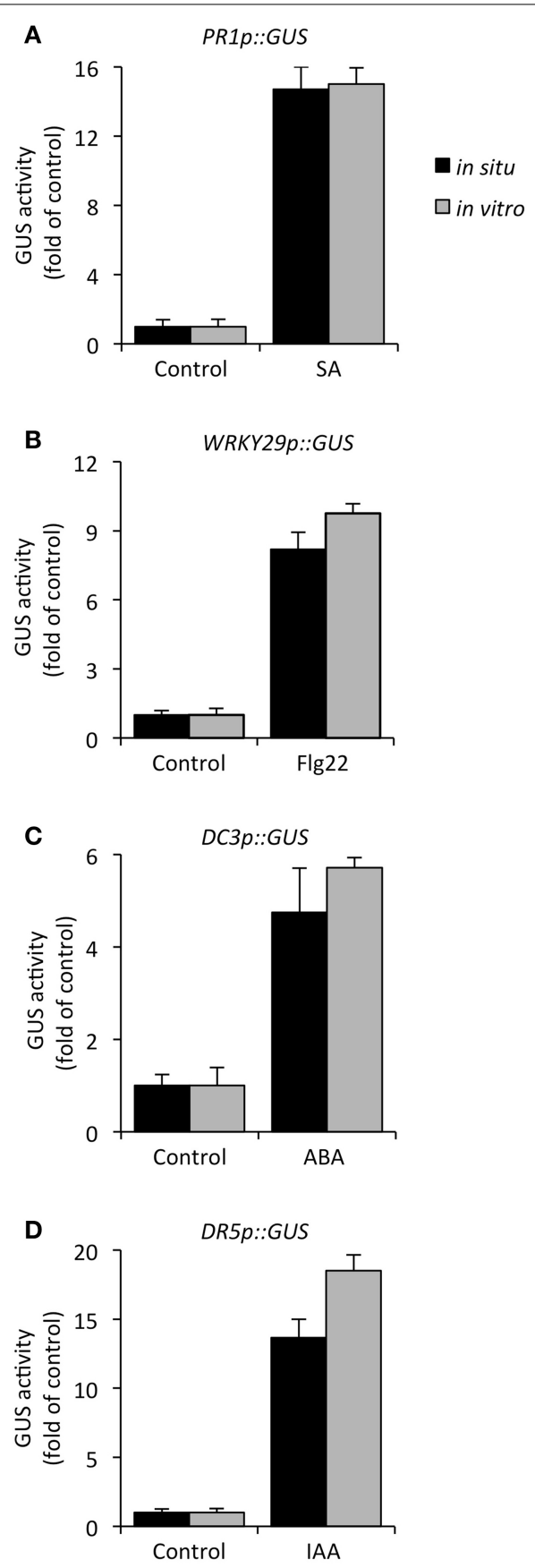

FIGURE 3 | Comparison of induced expression of diverse promoter-GUS reporter genes as determined by in situ and in vitro GUS assays. Twelve-day-old transgenic Arabidopsis seedlings were appropriately treated to obtain high reporter gene expression: (A) PR1p::GUS (200 $\mu \mathrm{M} \mathrm{SA}, 24 \mathrm{~h}$ ), (B) WRKY29p::GUS (1 $\mu \mathrm{M}$ flg22, $4 \mathrm{~h})$, (C) DC3p::GUS (100 $\mu \mathrm{M}$ ABA, $24 \mathrm{~h}$ ), and (D) DR5p::GUS (5 $\mu \mathrm{M}$ IAA, 4 h). GUS activity in situ (black bars) was determined after incubation of whole seedlings with the substrate 4-MUG $(1 \mathrm{mM})$ for $2 \mathrm{~h}$ and it is compared to GUS activity (initial rate) determined in vitro (gray bars) using protein extracts prepared from seedlings that were treated identically. For better comparison, the resulting activities in situ [relative light units (RLU) per assay] and in vitro (pmol $\mathrm{min}^{-1} \mathrm{mg}^{-1}$ protein) are normalized to untreated control samples, thus showing fold of induction in response to treatment. All values represent the mean $( \pm S D$ ) of four biological replicates. 


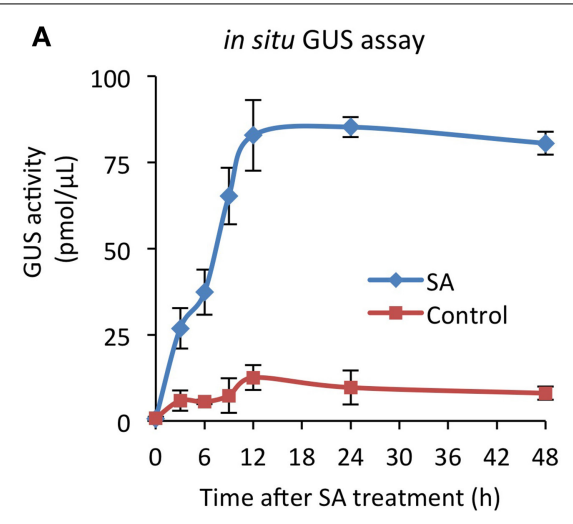

FIGURE 4 | Time course of PR1p::GUS expression upon treatment with SA. Arabidopsis seedlings harboring the SA-responsive PR1p::GUS reporter gene, grown for 12 days in liquid culture, were treated with $200 \mu \mathrm{M}$ SA (or $0.2 \%$ DMSO as control) for the indicated time periods. (A) GUS activity was determined with intact

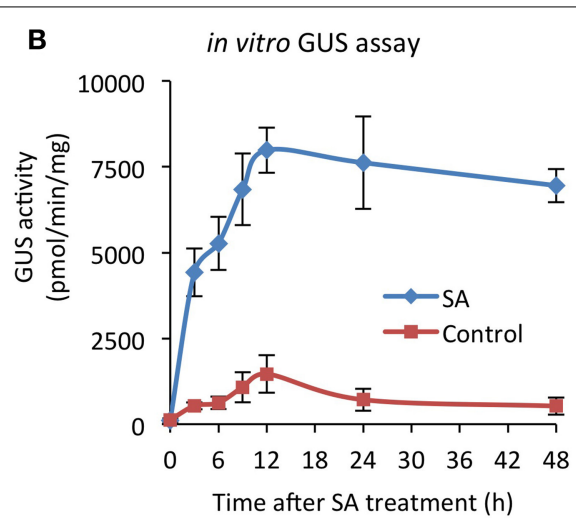

seedlings (in situ) and (B) in total extracts (in vitro) derived from seedlings of the same experiment. Specific activities are derived from 4-MU standard curves and are normalized to assay volume (A) or total extractable protein (B). All values represent the mean $( \pm S D$ ) of four biological replicates. treated with solvent (DMSO), only a low activity increase occurred.

For many biological applications it is necessary or useful to freeze samples for subsequent bioassays. We therefore explored whether the new GUS assay can also be performed with frozen seedlings without loss in performance. Therefore, PR1p::GUS seedlings were treated with SA $(200 \mu \mathrm{M})$ as before and at the end of the incubation period $(24 \mathrm{~h})$ half of the samples were used to quantify GUS activity immediately. The other half was transferred to Eppendorf tubes, frozen in liquid nitrogen and stored at $-80^{\circ} \mathrm{C}$ for 4 weeks. (Of note, for short-term storage samples can also be frozen directly in closed microplates). Without much thawing, seedlings were provided with substrate-containing lysis buffer and activity was recorded as before. The GUS activity determined in fresh and frozen seedling diverged by maximally $20 \%$ in both SA-treated and control samples (Figure 5).

We conclude, the described GUS activity assay for application with intact seedlings is robust and reliable and the facile acquisition of quantitative data makes it particularly suitable for application in large-scale screening programs.

\section{THE GUS PRODUCT 4-MU IS READILY RELEASED FROM THE PLANT TISSUE}

The functionality of the GUS assay with intact seedlings relies on the included detergents, Triton X-100, which facilitates penetration of substrate and product throughout the seedlings (Blázquez, 2007). To demonstrate that this is a valid assumption, we monitored whether the product of the reaction, 4-MU, indeed leaks out of the seedlings or stays within. To this end, we treated PR1p::GUS seedlings with various SA concentrations and after $24 \mathrm{~h}$ determined GUS activity (Figure 6A). From the results it is apparent that increasing SA caused higher PR1 gene expression, reaching a maximum at $200-300 \mu \mathrm{M}$ as previously reported (Bartsch et al., 2010). Higher SA concentrations were toxic and therefore no gene expression (GUS activity) was detectable. When from the same experiment, the seedlings were removed from the assay buffer, transferred to new microplates, and the fluorescence

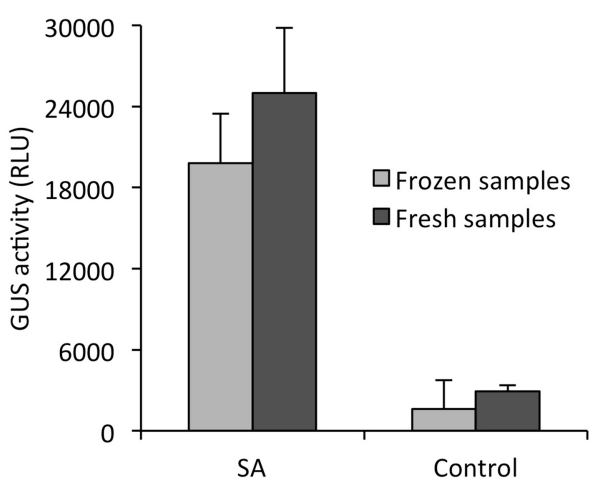

FIGURE 5 | Comparison of in situ GUS activity in fresh and frozen seedlings. Arabidopsis seedlings harboring the SA-responsive PR1p::GUS reporter gene, grown for 12 days in liquid culture, were treated with $200 \mu \mathrm{M}$ SA or $0.2 \%$ DMSO (control) for $24 \mathrm{~h}$. Half of the samples served for instant determination of GUS activity in situ (black bars) as described in Materials and Methods. The other half was frozen and stored at $-80^{\circ} \mathrm{C}$ for 4 weeks. For determining GUS activity, frozen seedlings were transferred to microplate wells prefilled with assay buffer containing $1 \mathrm{mM}$ 4-MUG and incubated for $90 \mathrm{~min}$ before quantifying 4-MU fluorescence. Activity is given in relative light units (RLU) emitted from total assays and all values represent the mean $( \pm S D$ ) of four biological replicates.

emanating from the seedlings and the assay buffer was separately recorded, we observed that the entire signal was almost exclusively associated with the solution (Figure 6B). This indicates that the enzyme's product, 4-MU, is readily released from the plant tissue and collected in the medium.

\section{CHEMICAL LIBRARY SCREENING WITH GUS ASSAY IN INTACT SEEDLINGS}

To demonstrate the general suitability of the new GUS assay methodology for chemical library screening with intact seedlings harboring inducible GUS reporter constructs, we performed a pilot screen with just 40 selected compounds, which fit in one 96well microplate when assayed in duplicates. The general design 


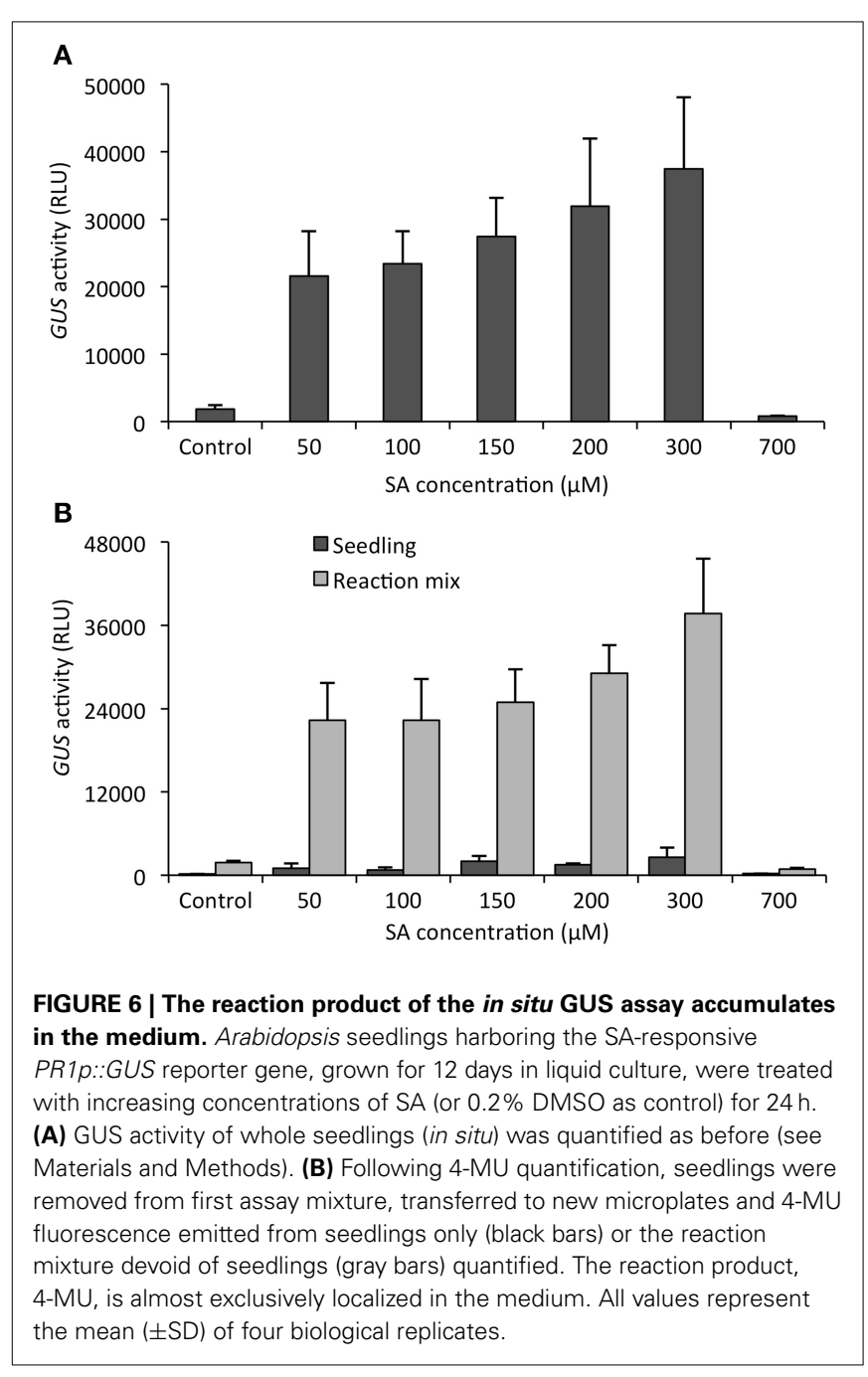

of the screening plate, which should also be adopted for largescale screening campaigns comprising several thousand chemicals, is shown in Figure 1; it includes positive (SA treatment) and negative (DMSO) controls alternating in the first and last column. Since we used an inducible GUS reporter system, it could be applied for bidirectional screening for either activators of gene expression or inhibitors that impair induced gene expression.

However, before proceeding directly to screening data analysis, we first assessed the quality of our assay conditions to ensure that the resulting data meet the minimum standards and permit legitimate conclusions. Therefore, we calculated the $Z^{\prime}$ factor, which is a common quality metric for evaluation and validation of high-throughput screening assays (Zhang et al., 1999; Birmingham et al., 2009), using the eight positive and eight negative control values included in each of the two screening plates (cf. Figure 1). The high-value (SA treated) control (RLU = $42,826 \pm 5342$ and $37,266 \pm 2480$ ) and low-value (DMSO treated) control $(\mathrm{RLU}=1243 \pm 459$ and $2294 \pm 711)$ represent the screening window (Supplementary Figures 1A,B) and yielded $Z$ ' factors of 0.58 and 0.73 , respectively. By exceeding the value of 0.5 , this clearly defines the SA-induced PR1p::GUS expression as an excellent assay for chemical screening purposes, when using the established conditions for in situ quantification of GUS activity.

In the screen for activators of PR1p::GUS expression, 12day-old seedlings were treated with chemicals at $20 \mu \mathrm{M}$ for $24 \mathrm{~h}$ followed by instant quantification of GUS activity. Only one constituent of the library, which was identified as acetylsalicylic acid (ASA, 32), also named aspirin, caused an appreciable increase in GUS activity (Figure 7A). ASA has previously been demonstrated to activate plant defense responses, similar to SA (White, 1979; Spoel et al., 2003; Loake and Grant, 2007). Importantly, the recorded activity was about 8 -fold higher than the negative control values (RLU $=1243 \pm 459)$ and about $25 \%$ of the positive control values obtained with $200 \mu \mathrm{M} \mathrm{SA}(\mathrm{RLU}=42,826 \pm 5342)$ (Figure 7A and Supplementary Figure 1A). To gain further confidence in our hit selection, we also calculated the $Z$ score, which serves to normalize the data and also provides explicit information on the variation in sample and control measurements (Malo et al., 2006; Birmingham et al., 2009). Hit compounds are selected on the basis of a threshold value, which is typically set to a $Z$ score of 2-3, i.e., $S D$ above or below the normalized mean $(Z$ score $=0)$. With a $Z$ score $>5$, ASA can be classified as strong hit, whereas weak candidates [e.g., compound 34 (cycloheximide, $\mathrm{CHX}$ ) with a $Z$ score $\approx 1$ ] would require confirmation by additional experiments (Figure 7B).

In the screen for inhibitors of $P R 1 p:: G U S$ expression, seedlings were pre-incubated with the library constituents for $1 \mathrm{~h}$ before addition of $200 \mu \mathrm{M} \mathrm{SA}$ and quantifying GUS activity after $24 \mathrm{~h}$ as before. From the raw data it appears as if the variation of induced activity is relatively high (Figure 8A); however, the coefficient of variation $(C v=\sigma / \mu)$ is only 0.15 when calculated across the whole screening plate, which compares favorably with the corresponding $C v$ value of 0.25 for non-induced activities (e.g., screening plate for activators, cf. Figure 7A). Irrespectively, the translational inhibitor CHX $\mathbf{3 4}$ was clearly identified as a strong hit, as also apparent after $Z$ score transformation of the activity data, which yields a value $<-2$ (Figure 8B). By contrast, the mycotoxin neosolaniol 23, which also impairs protein translation (Serrano et al., 2010), and thiomersal 37, an antiseptic and antifungal agent, showed up as relatively weak inhibitors. This is also apparent from their $Z$ scores of approximately -1 (Figure 8B). Again, the validation of such weak inhibitors would require additional experiments, such as determination of concentration dependency, bioavailability and/or stability, which is beyond the scope of this paper. The structures of all the compounds acting as activators or inhibitors of $P R 1$ expression identified in this small pilot screen are shown in Figure 9.

As a final step to further characterize the outlined screening methodology, we generated a replicate correlation plot to visualize the overall reproducibility (Figure 10). The calculated Pearson's correlation coefficient $(r=0.94)$ for both primary screens is a quality metric and demonstrates a good overall reproducibility and reliability of replicates. From this we conclude that the GUS activity assay with intact seedlings provides quantitative data of sufficient robustness and accuracy to allow confident hit identification in chemical screening campaigns. 


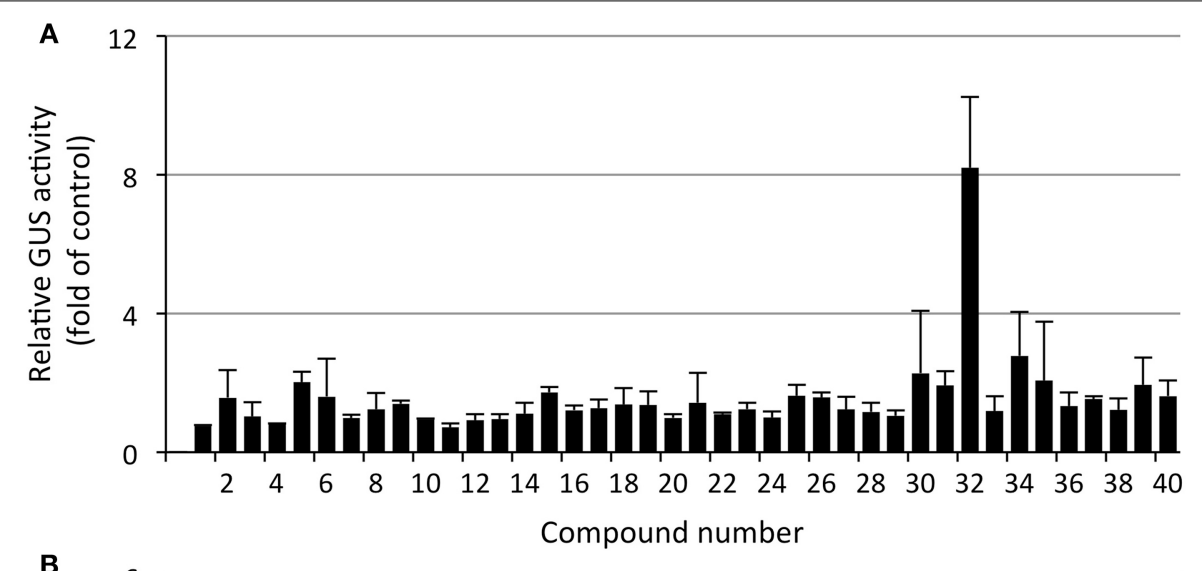

B

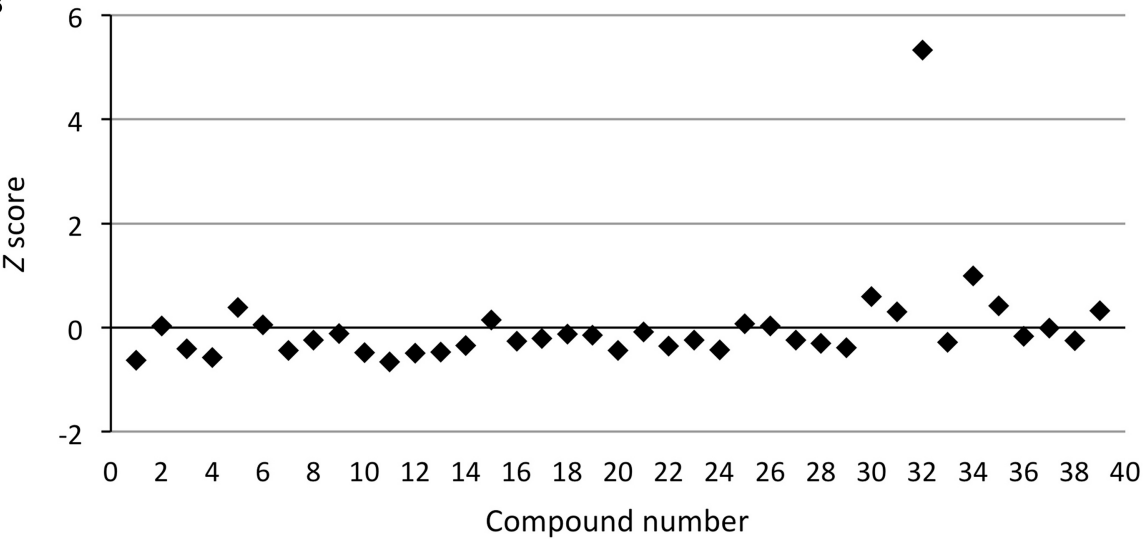

FIGURE 7 | Screening for activators of SA signaling. Arabidopsis seedlings harboring the SA-responsive PR1p::GUS reporter gene, grown for 12 days in liquid culture, were treated with 40 diverse chemicals $(20 \mu \mathrm{M})$ for $24 \mathrm{~h}$. (A) GUS activity of whole seedlings (in situ) was quantified by incubation with 4-MUG (1 mM) for 90 min (see Materials and Methods) and normalized to the control samples (DMSO treated). Values represent the mean of duplicate samples and the error bars indicate the corresponding high and low values.
One compound (32, acetylsalicylic acid) appeared as strong activator of reporter gene expression, causing 8-fold induction. (B) Z score transformation of the screening data (see Materials and Methods) likewise identifies compound $\mathbf{3 2}$ as strong hit $(Z>5)$, whereas compound $\mathbf{3 4}$ (cycloheximide) is a marginal hit $(Z \approx 1)$, which requires confirmation and further validation. The raw activity data of this screen are presented in Supplementary Figure $1 \mathrm{~A}$.

\section{DISCUSSION}

Here, we have established and validated a new forward chemical genetic screening method using intact $A$. thaliana seedlings harboring diverse GUS reporter constructs for direct quantification of GUS activity. Its direct application in the microplate format used for seedling growth requires only a minimum of sample handling and allows automatic acquisition of quantitative data, which are a prerequisite for unbiased identification of hits via numeric threshold values derived from statistical procedures (Malo et al., 2006; Birmingham et al., 2009). Clearly, this approach is superior over frequently used qualitative screening approaches that are based on visual evaluation of GUS stained tissue, which is prone to biased hit selection (Hayashi et al., 2003; Armstrong et al., 2004; Serrano et al., 2007; Gendron et al., 2008; Knoth et al., 2009; Kim et al., 2011). Likewise, the outlined procedure is superior to other quantitative GUS assays carried out in vitro, which rely on tissue extraction and, although accurate, are much more labor-intensive and time-consuming. The screening methodology we describe is facile, accurate, reliable, and robust and therefore suitable for high-throughput screening projects. Although this method monitors activity only in situ (rather than in vivo) it compares well with the luciferase reporter system, which allows true activity recording in vivo and therefore represents the most frequently used screening tool in drug discovery programs (Inglese et al., 2007). However, in plants, including Arabidopsis, GUS is still the prevailing reporter system in use and therefore the outlined procedure may find frequent application.

To demonstrate the reliability and robustness of the in situ GUS quantification with intact seedlings, we directly compared it to the conventional, frequently used quantitative in vitro GUS assay. Using different inducible GUS reporter lines, we observed similar patterns of substrate conversion in both assays. However, the GUS activity recorded in situ cannot easily be normalized to protein content or fresh weight without compromising on its ease and simplicity, but molar conversion rates can be obtained from the emitted RLU by its relation to a standard curve with known product (4-MU) concentrations. Although signal intensity is affected by seedling size, the observed variability of recorded GUS activity in replicate samples is not exceeding that of the normalized GUS activity determined in vitro (cf. Figures 1,2$)$. The 

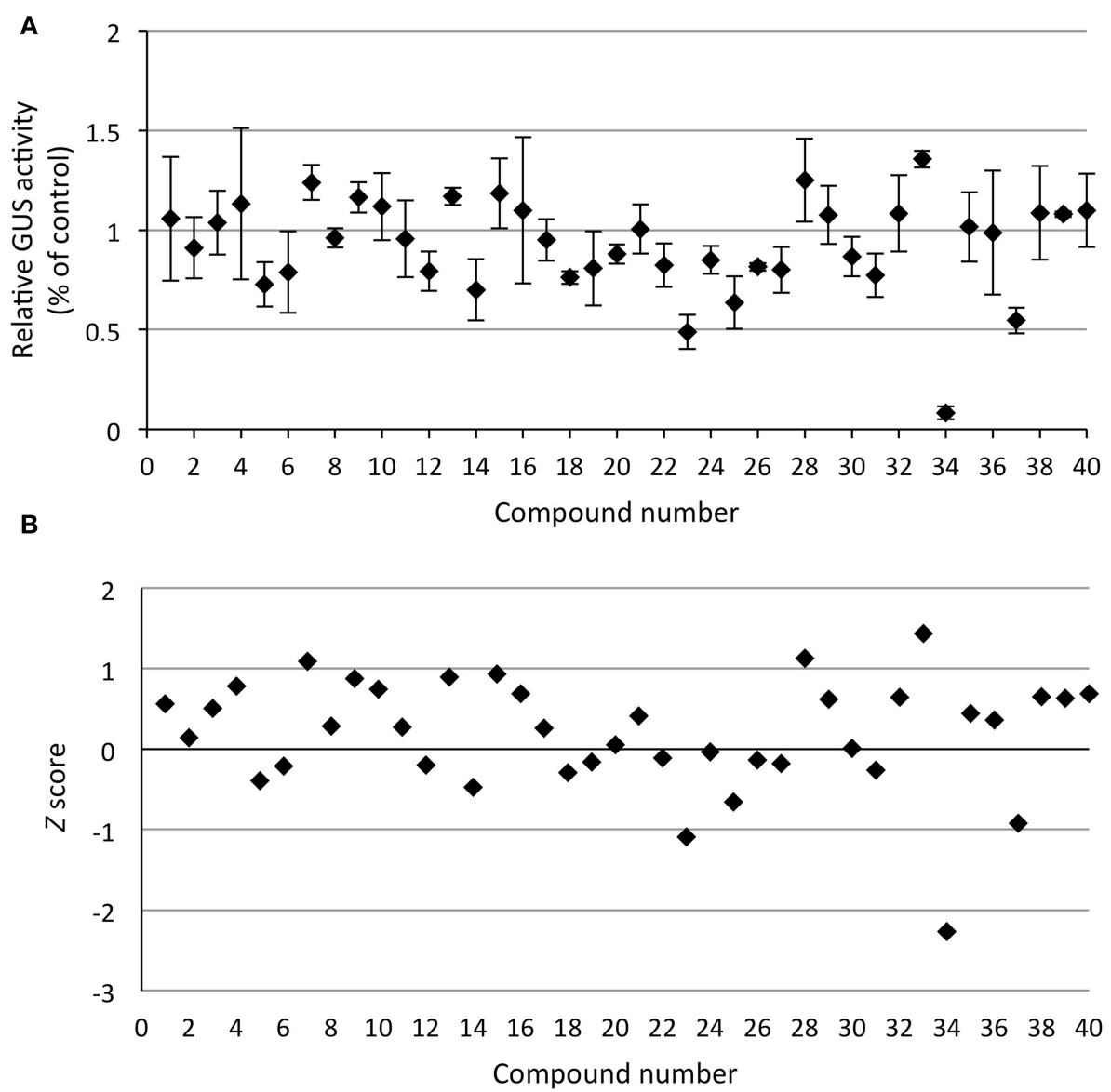

FIGURE 8 | Screening for inhibitors of SA signaling. Arabidopsis seedlings harboring the SA-responsive PR1p::GUS reporter gene, grown for 12 days in liquid culture, were treated with 40 diverse chemicals $(20 \mu \mathrm{M})$ for $1 \mathrm{~h}$ prior to addition of SA $(200 \mu \mathrm{M})$ to induce reporter gene expression. (A) GUS activity of whole seedlings (in situ) was quantified by incubation with 4-MUG (1 mM) for $90 \mathrm{~min}$ (see Materials and Methods) and normalized to the SA-treated control samples. Values represent the mean of duplicate samples and the error bars indicate the corresponding high and low values. One compound (34, cycloheximide) appeared as strong inhibitor of reporter gene expression. (B) $Z$ score transformation of the screening data (see Materials and Methods) likewise identifies compound $\mathbf{3 4}$ as strong hit $(Z<-2)$, whereas compounds $\mathbf{2 3}$ (neosolaniol) and $\mathbf{3 7}$ (thiomersal) are marginal hits $(Z \approx-1)$, which require confirmation and further validation. The raw activity data of this screen are presented in Supplementary Figure 1B. same conclusion is derived from the high correlation coefficient $(r=0.94)$ of replicate samples, demonstrating high accuracy and reproducibility of GUS activity quantification. Furthermore, the in situ GUS assay is suitable for application to a large variety of GUS reporter lines, irrespective of their particular cell-type and organ-specific expression patterns and modes of regulation. This is not only true for the four reporter lines used in this study (Supplementary Figure 2), but also for several additional lines that we currently apply in various experiments.

To further affirm the suitability of the described GUS assay for chemical screening projects, we employed it in a small pilot screen using seedlings of the PR1p::GUS reporter line in search for modulators of SA signaling. Both a strong activator, ASA, and a strong inhibitor, $\mathrm{CHX}$, of reporter gene expression were identified with high confidence via their modulation of GUS activity (Figures 7, 8). The bioactivity of both types of compound has previously been described (White, 1979; Spoel et al., 2003; Loake and Grant, 2007; Serrano et al., 2010; Meesters et al., 2014), here they served as positive and negative controls, respectively. The major advantage of the method, however, lies in the acquisition of quantitative expression data, which allows application of statistical tools for unbiased hit selection (Malo et al., 2006; Birmingham et al., 2009). In addition, quantitative screening data permit to distinguish between compounds with high and low potency, which may be useful for subsequent experimental strategies aiming at the discovery of new bioactive scaffolds. However, such weak activities as uncovered here need further critical evaluation.

In conclusion, we provided an efficient, facile, reliable and robust screening methodology, based on quantitative estimation of GUS activity in intact Arabidopsis seedlings, which can easily be adopted for any transgenic line harboring the GUS reporter. The acquisition of quantitative data in combination with the ease of sample and assay handling compare favorably with the convenience of truly in vivo activity monitoring systems such as luciferase or fluorescent proteins (GFP, RFP, etc.) and therefore 


\section{Activators of $P R 1$ expression}<smiles>O=C(O)c1ccccc1O</smiles><smiles>CC(=O)Oc1ccccc1C(=O)O</smiles>

Salicylic acid (SA) Acetylsalicylic acid (32)

Inhibitors of $P R 1$ expression

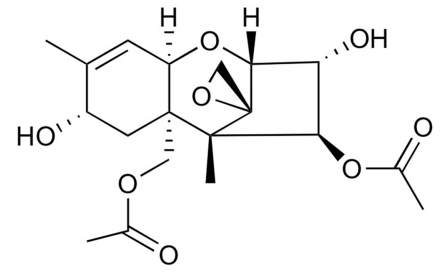

Neosolaniol (23)<smiles>C[C@H]1C[C@H](C)C(=O)[C@@H]([C@H](O)CC2CC(=O)NC(=O)C2)C1</smiles>

Cycloheximide (34)<smiles>CCOSc1ccccc1C(=O)O</smiles>

Thiomersal (37)

FIGURE 9 | Structures of bioactive compounds modulating PR1 gene expression. Examples refer to compounds mentioned in this paper that were identified in the small pilot screen described.

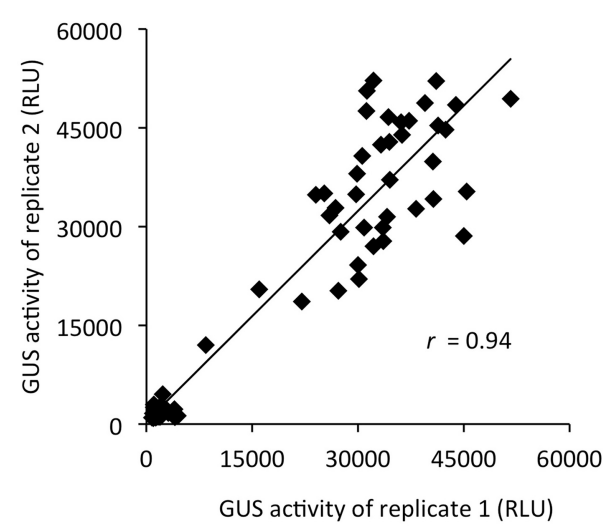

FIGURE 10 | Replicate correlation plot of screening data. The raw activity values, replicate 1 and 2 , of the two pilot screening plates for activators and inhibitors of PR1p::GUS expression were plotted against each other. The high value of Pearson's correlation coefficient $(r=0.94)$ indicates that the in situ GUS assay is robust, reliable and provides reproducible screening data.

the outlined methodology has great potential for broad application particularly in time- and labor-intensive large-scale chemical screening campaigns.

\section{ACKNOWLEDGMENTS}

We thank the Max Planck Society for funding this work and the members of the chemical biology laboratory, in particular Dr. C. Meesters for critical reading of the manuscript and stimulating discussions and Brigitte Pickel for excellent technical assistance. Vivek Halder is recipient of a DAAD scholarship (A/10/74508).

\section{SUPPLEMENTARY MATERIAL}

The Supplementary Material for this article can be found online at: http://www.frontiersin.org/journal/10.3389/fpls.2015. 00013/abstract

\section{REFERENCES}

Ancillo, G., Hoegen, E., and Kombrink, E. (2003). The promoter of the potato chitinase $C$ gene directs expression to epidermal cells. Planta 217, 566-576. doi: 10.1007/s00425-003-1029-0

Armstrong, J. I., Yuan, S., Dale, J. M., Tanner, V. N., and Theologis, A. (2004). Identification of inhibitors of auxin transcriptional activation by means of chemical genetics in Arabidopsis. Proc. Natl. Acad. Sci. U.S.A. 101, 14978-14983. doi: 10.1073/pnas.0404312101

Bartsch, M., Bednarek, P., Vivancos, P. D., Schneider, B., von Roepenack-Lahaye, E., Foyer, C. H., et al. (2010). Accumulation of isochorismate-derived 2,3dihydroxybenzoic 3-O- $\beta$-D-xyloside in Arabidopsis resistance to pathogens and ageing of leaves. J. Biol. Chem. 285, 25654-25665. doi: 10.1074/jbc.M109.092569

Birmingham, A., Selfors, L. M., Forster, T., Wrobel, D., Kennedy, C. J., Shanks, E., et al. (2009). Statistical methods for analysis of high-throughput RNA interference screens. Nat. Methods 6, 569-575. doi: 10.1038/nmeth.1351

Blackwell, H. E., and Zhao, Y. (2003). Chemical genetic approaches to plant biology. Plant Physiol. 133, 448-455. doi: 10.1104/pp.103.031138

Blázquez, M. (2007). Quantitative GUS activity assay in intact plant tissue. CSH Protoc. 2007:pdb.prot4688. doi: 10.1101/pdb.prot468

Bradford, M. M. (1976). A rapid and sensitive method for the quantification of microgram quantities of protein utilizing the principle of protein-dye binding. Anal. Biochem. 72, 248-254. doi: 10.1016/0003-2697(76)90527-3

Chak, R. K. F., Thomas, T. L., Quatrano, R. S., and Rock, C. D. (2000). The genes $A B I 1$ and $A B I 2$ are involved in abscisic acid- and drought-inducible expression of the Daucus carota L. Dc3 promoter in guard cells of transgenic Arabidopsis thaliana (L.) Heynh. Planta 210, 875-883. doi: 10.1007/s004250050692

Cutler, S. R., Rodriguez, P. L., Finkelstein, R. R., and Abrams, S. R. (2010). Abscisic acid: emergence of a core signaling network. Annu. Rev. Plant Biol. 61, 651-679. doi: 10.1146/annurev-arplant-042809-112122

DeBolt, S., Gutierrez, R., Ehrhardt, D. W., Melo, C. V., Ross, L., Cutler, S. R., et al. (2007). Morlin, an inhibitor of cortical microtubule dynamics and cellulose synthase movement. Proc. Natl. Acad. Sci. U.S.A. 104, 5854-5859. doi: 10.1073/pnas.0700789104 
De Rybel, B., Audenaert, D., Vert, G., Rozhon, W., Mayerhofer, J., Peelman, F., et al. (2009). Chemical inhibition of a subset of Arabidopsis thaliana GSK3like kinases activates brassinosteroid signaling. Chem. Biol. 16, 594-604. doi: 10.1016/j.chembiol.2009.04.008

Desprez, T., Vernhettes, S., Fagard, M., Refrégier, G., Desnos, T., Aletti, E., et al. (2002). Resistance against herbicide isoxaben and cellulose deficiency caused by distinct mutations in same cellulose synthase isoform CESA6. Plant Physiol. 128, 482-490. doi: 10.1104/pp.010822

Forde, B. G., Cutler, S. R., Zaman, N., and Krysan, P. J. (2013). Glutamate signalling via a MEKK1 kinase-dependent pathway induces changes in Arabidopsis root architecture. Plant J. 75, 1-10. doi: 10.1111/tpj.12201

Gendron, J. M., Haque, A., Gendron, N., Chang, T., Asami, T., and Wang, Z.-Y. (2008). Chemical genetic dissection of brassinosteroid-ethylene interaction. Mol. Plant 1, 368-379. doi: 10.1093/mp/ssn005

Hayashi, K.-I., Jones, A. M., Ogino, K., Yamazoe, A., Oono, Y., Inoguchi, M., et al. (2003). Yokonolide B, a novel inhibitor of auxin action, blocks degradation of AUX/IAA factors. J. Biol. Chem. 278, 23797-23806. doi: 10.1074/jbc.M300299200

Hayashi, K.-I., Tan, X., Zheng, N., Hatate, T., Kimura, Y., Kepinski, S., et al. (2008). Small-molecule agonists and antagonists of F-box protein-substrate interactions in auxin perception and signaling. Proc. Natl. Acad. Sci. U.S.A. 105, 5632-5637. doi: 10.1073/pnas.0711146105

Hicks, G. R., and Raikhel, N. V. (2009). Opportunities and challenges in plant chemical biology. Nat. Chem. Biol. 5, 268-272. doi: 10.1038/nchembio0509-268

Hicks, G. R., and Raikhel, N. V. (2012). Small molecules present large opportunities in plant biology. Annu. Rev. Plant Biol. 63, 261-282. doi: 10.1146/annurevarplant-042811-105456

Hicks, G. R., and Raikhel, N. V. (2014). Plant chemical biology: are we meeting the promise? Front. Plant Sci. 5:455. doi: 10.3389/fpls.2014.00455

Inglese, J., Johnson, R. L., Simeonov, A., Xia, M., Zheng, W., Austin, C. P., et al. (2007). High-throughput screening assays for the identification of chemical probes. Nat. Chem. Biol. 3, 466-479. doi: 10.1038/nchembio.2007.17

Jefferson, R. A., Kavanagh, T. A., and Bevan, M. W. (1987). GUS fusions: $\beta$-glucuronidase as a sensitive and versatile gene fusion marker in higher plants. EMBO J. 6, 3901-3907.

Kaschani, F., and van der Hoorn, R. (2007). Small molecule approaches in plants. Curr. Opin. Chem. Biol. 11, 88-98. doi: 10.1016/j.cbpa.2006.11.038

Kim, J.-Y., Henrichs, S., Bailly, A., Vincenzetti, V., Sovero, V., Mancuso, S., et al. (2010). Identification of an ABCB/P-glycoprotein-specific inhibitor of auxin transport by chemical genomics. J. Biol. Chem. 285, 23309-23317. doi: 10.1074/jbc.M110.105981

Kim, T.-H., Hauser, F., Ha, T., Xue, S., Böhmer, M., Nishimura, N., et al. (2011). Chemical genetics reveals negative regulation of abscisic acid signaling by a plant immune response pathway. Curr. Biol. 21, 990-997. doi: 10.1016/j.cub.2011.04.045

Knoth, C., Salus, M. S., Girke, T., and Eulgem, T. (2009). The synthetic elicitor 3,5-dichloroanthranilic acid induces NPR1-dependent and NPR1-independent mechanisms of disease resistance in Arabidopsis. Plant Physiol. 150, 333-347. doi: 10.1104/pp.108.133678

Loake, G., and Grant, M. (2007). Salicylic acid in plant defence-the players and protagonists. Curr. Opin. Plant Biol. 10, 466-472. doi: 10.1016/j.pbi.2007.08.008

Malo, N., Hanley, J. A., Cerquozzi, S., Pelletier, J., and Nadon, R. (2006). Statistical practice in high-throughput screening data analysis. Nat. Biotechnol. 24, 167-175. doi: 10.1038/nbt1186

Meesters, C., Mönig, T., Oeljeklaus, J., Krahn, D., Westfall, C. S., Hause, B., et al. (2014). A chemical inhibitor of jasmonate signaling targets JAR1 in Arabidopsis thaliana. Nat. Chem. Biol. 10, 830-836. doi: 10.1038/nchembio.1591

Melcher, K., Ng, L.-M., Zhou, X. E., Soon, F.-F., Xu, Y., Suino-Powell, K. M., et al. (2009). A gate-latch-lock mechanism for hormone signalling by abscisic acid receptors. Nature 462, 602-608. doi: 10.1038/nature08613

Motte, H., Galuszka, P., Spíchal, L., Tarkowski, P., Plíhal, O., Šmehilová, M., et al. (2013). Phenyl-adenine, identified in a LIGHT-DEPENDENT SHORT HYPOCOTYLS4-assisted chemical screen, is a potent compound for shoot regeneration through the Inhibition of CYTOKININ OXIDASE/DEHYDROGENASE activity. Plant Physiol. 161, 1229-1241. doi: 10.1104/pp.112.210716

Murashige, T., and Skoog, F. (1962). A revised medium for rapid growth and bio assays with tobacco tissue cultures. Physiol. Plant. 15, 473-497. doi: 10.1111/j.1399-3054.1962.tb08052.x
Noutoshi, Y., Okazaki, M., Kida, T., Nishina, Y., Morishita, Y., Ogawa, T., et al. (2012). Novel plant immune-priming compounds identified via high-throughput chemical screening target salicylic acid glucosyltransferases in Arabidopsis. Plant Cell 24, 3795-3804. doi: 10.1105/tpc.112. 098343

Park, E., Díaz-Moreno, S. M., Davis, D. J., Wilkop, T. E., Bulone, V., and Drakakaki, G. (2014). Endosidin 7 specifically arrests late cytokinesis and inhibits callose biosynthesis, revealing distinct trafficking events during cell plate maturation. Plant Physiol. 165, 1019-1034. doi: 10.1104/pp.114.241497

Park, S.-Y., Fung, P., Nishimura, N., Jensen, D. R., Fujii, H., Zhao, Y., et al. (2009). Abscisic acid inhibits type 2C protein phosphatases via the PYR/PYL family of START proteins. Science 324, 1068-1071. doi: 10.1126/science. 1173041

Raikhel, N., and Pirrung, M. (2005). Adding precision tools to the plant biologists' toolbox with chemical genomics. Plant Physiol. 138, 563-564. doi: 10.1104/pp.104.900155

Rojas-Pierce, M., Titapiwatanakun, B., Sohn, E. J., Fang, F., Larive, C. K., Blakeslee, J., et al. (2007). Arabidopsis P-glycoprotein19 participates in the inhibition of gravitropism by gravacin. Chem. Biol. 14, 1366-1376. doi: 10.1016/j.chembiol.2007.10.014

Santiago, J., Dupeux, F., Round, A., Antoni, R., Park, S.-Y., Jamin, M., et al. (2009). The abscisic acid receptor PYR1 in complex with abscisic acid. Nature 462, 665-668. doi: 10.1038/nature08591

Schreiber, K., Ckurshumova, W., Peek, J., and Desveaux, D. (2008). A highthroughput chemical screen for resistance to Pseudomonas syringae in Arabidopsis. Plant J. 54, 522-531. doi: 10.1111/j.1365-313X.2008. 03425.x

Serrano, M., Hubert, D. A., Dangl, J. L., Schulze-Lefert, P., and Kombrink, E. (2010). A chemical screen for suppressors of the avrRpm1-RPM1dependent hypersensitive cell death response in Arabidopsis thaliana. Planta 231, 1013-1023. doi: 10.1007/s00425-010-1105-1

Serrano, M., Robatzek, S., Torres, M., Kombrink, E., Somssich, I. E., Robinson, M., et al. (2007). Chemical interference of pathogen-associated molecular patterntriggered immune responses in Arabidopsis reveals a potential role for fatty-acid synthase type II complex-derived lipid signals. J. Biol. Chem. 282, 6803-6811. doi: 10.1074/jbc.M608792200

Shapiro, A. D., and Zhang, C. (2001). The role of NDR1 in avirulence gene-directed signaling and control of programmed cell death in Arabidopsis. Plant Physiol. 127, 1089-1101. doi: 10.1104/pp.010096

Spoel, S. H., Koornneef, A., Claessens, S. M. C., Korzelius, J. M. P., Van Pelt, J. A., and Pieterse, C. M. J. (2003). NPR1 modulates cross-talk between salicylate- and jasmonate-dependent defense pathways through a novel function in the cytosol. Plant Cell 15, 760-770. doi: 10.1105/tpc.009159

Sprenger-Haussels, M., and Weisshaar, B. (2000). Transactivation properties of parsley proline-rich bZIP transcription factors. Plant J. 22, 1-8. doi: 10.1046/j.1365-313x.2000.00687.x

Stockwell, B. R. (2004). Exploring biology with small organic molecules. Nature 432, 846-854. doi: 10.1038/nature03196

Surpin, M., Rojas-Pierce, M., Carter, C., Hicks, G. R., Vasquez, J., and Raikhel, N. V. (2005). The power of chemical genomics to study the link between endomembrane system components and the gravitropic response. Proc. Natl. Acad. Sci. U.S.A. 102, 4902-4907. doi: 10.1073/pnas.0500222102

Tóth, R., Gerding-Reimers, C., Deeks, M. J., Menninger, S., Gallegos, R. M., Tonaco, I. A. N., et al. (2012). Prieurianin/endosidin 1 is an actin-stabilizing small molecule identified from a chemical genetic screen for circadian clock effectors in Arabidopsis thaliana. Plant J. 71, 338-352. doi: 10.1111/j.1365313X.2012.04991.x

Tóth, R., and van der Hoorn, R. A. L. (2010). Emerging principles in plant chemical genetics. Trends Plant Sci. 15, 81-88. doi: 10.1016/j.tplants.2009. 11.005

Tsuda, K., Mine, A., Bethke, G., Igarashi, D., Botanga, C. J., Tsuda, Y., et al. (2013). Dual regulation of gene expression mediated by extended MAPK activation and salicylic acid contributes to robust innate immunity in Arabidopsis thaliana. PLoS Genet. 9:e1004015. doi: 10.1371/journal.pgen.10 04015

Ulmasov, T., Murfett, J., Hagen, G., and Guilfoyle, T. J. (1997). Aux/IAA proteins repress expression of reporter genes containing natural and highly active synthetic auxin response elements. Plant Cell 9, 1963-1971. doi: 10.1105/tpc.9.11.1963 
Vlot, A. C., Dempsey, D. M. A., and Klessig, D. F. (2009). Salicylic acid, a multifaceted hormone to combat disease. Annu. Rev. Phytopathol. 47, 177-206. doi: 10.1146/annurev.phyto.050908.135202

Walsh, T. A., Neal, R., Merlo, A. O., Honma, M., Hicks, G. R., Wolff, K., et al. (2006). Mutations in an auxin receptor homolog AFB5 and in SGT1b confer resistance to synthetic picolinate auxins and not to 2,4-dichlorophenoxyacetic acid or indole-3-acetic acid in Arabidopsis. Plant Physiol. 142, 542-552. doi: 10.1104/pp.106.085969

White, R. F. (1979). Acetylsalicylic acid (aspirin) induces resistance to tobacco mosaic virus in tobacco. Virology 99, 410-412. doi: 10.1016/00426822(79)90019-9

Yoneda, A., Higaki, T., Kutsuna, N., Kondo, Y., Osada, H., Hasezawa, S., et al. (2007). Chemical genetic screening identifies a novel inhibitor of parallel alignment of cortical microtubules and cellulose microfibrils. Plant Cell Physiol. 48, 1393-1403. doi: 10.1093/pcp/pcm 120

Zhang, J.-H., Chung, T. D. Y., and Oldenburg, K. R. (1999). A simple statistical parameter for use in evaluation and validation of high throughput screening assays. J. Biomol. Screen. 4, 67-73. doi: 10.1177/108705719900400206

Zhao, Y., Dai, X., Blackwell, H. E., Schreiber, S. L., and Chory, J. (2003). SIR1, an upstream component in auxin signaling identified by chemical genetics. Science 301, 1107-1110. doi: 10.1126/science.1084161
Zouhar, J., Hicks, G. R., and Raikhel, N. V. (2004). Sorting inhibitors (Sortins): chemical compounds to study vacuolar sorting in Arabidopsis. Proc. Natl. Acad. Sci. U.S.A. 101, 9497-9501. doi: 10.1073/pnas.0402121101

Conflict of Interest Statement: The authors declare that the research was conducted in the absence of any commercial or financial relationships that could be construed as a potential conflict of interest.

Received: 06 November 2014; paper pending published: 25 November 2014; accepted: 07 January 2015; published online: 29 January 2015.

Citation: Halder V and Kombrink E (2015) Facile high-throughput forward chemical genetic screening by in situ monitoring of glucuronidase-based reporter gene expression in Arabidopsis thaliana. Front. Plant Sci. 6:13. doi: 10.3389/fpls.2015.00013

This article was submitted to Plant Physiology, a section of the journal Frontiers in Plant Science.

Copyright (c) 2015 Halder and Kombrink. This is an open-access article distributed under the terms of the Creative Commons Attribution License (CC BY). The use, distribution or reproduction in other forums is permitted, provided the original author(s) or licensor are credited and that the original publication in this journal is cited, in accordance with accepted academic practice. No use, distribution or reproduction is permitted which does not comply with these terms. 